\title{
Emprego formal na Bahia na primeira década do século XXI: caminhou-se na direção do trabalho decente? ${ }^{1}$
}

Laumar Neves de Soura

Programa de Pós-Graduação em Desenvolvimento Regional e Urbano da Universidade Salvador (UNIFACS)

Recebido: 25/06/2013 Versão revisada (entregue): 25/11/2013 Aprovado: 28/11/2013

\begin{abstract}
Resumo
O objetivo neste artigo é procurar, nas estatísticas referentes à evolução do trabalho formal no estado da Bahia, entre os anos de 2000 e 2010, evidências que permitam avaliar a qualidade dos postos de trabalhos que foram criados nesse horizonte temporal. O propósito é reunir elementos que indiquem em que medida essas vagas, vistas em conjunto, aproximaram-se e/ou se afastaram de alguns dos diferentes sentidos atribuídos ao conceito de trabalho decente. Para dar conta dessa tarefa recorreu-se aos dados disponibilizados pela Relação Anual de Informações Sociais (RAIS). A hipótese que norteia a construção dos argumentos assenta-se na ideia de que trabalho formal não pode ser tomado como sinônimo de trabalho decente. Isso porque, por mais que esse primeiro tipo trabalho (socialmente protegido) aproxime-se e/ou encerre o paradigma de trabalho decente, ele não consegue revelar, na sua integridade, o sentido que o termo decente procura exprimir.
\end{abstract}

Palavras-chave | Economia baiana; emprego formal; século XXI; trabalho decente; trabalho formal.

Código JEL | J21; J80; O17.

\section{FORMAL EMPLOYMENT IN BAHIA IN THE FIRST DECADE OF THE 21TH CENTURY: STEPS TOWARDS DECENT WORK?}

\begin{abstract}
The main purpose in this article is to evaluate the quality of jobs created in the Brazilian State of Bahia between 2000 and 2010 based on the statistics relating to the evolution of formal work. The intention is to gather evidence for identifying to what extent these jobs, taken together, neared or distanced from some meanings given to the concept of decent work. For this we used the data available by the Annual Report of Social Information (RAIS). The hypothesis that guides the construction of the arguments is based on the idea that formal work cannot be taken
\end{abstract}

\footnotetext{
${ }^{1}$ Uma versão inicial deste artigo foi apresentada no XV Encontro da ANPUR, em Recife, no dia 21 de maio de 2013.
} 
as synonym of decent work. As much as formal, socially protected work comes close to the paradigm of decent work, it cannot fully reveal the true meaning that the term decent tries to express.

Keywords | Bahia's economy; decent work; formal employment; formal job; 21th century.

JEL-Code | J21; J80; O17.

\section{EMPLEO FORMAL EN BAHIA EN LA PRIMER DÉCADA DEL SIGLO XXI: SE DIERON PASOS HACIA EL TRABAJO DECENTE?}

\section{Resumen}

Con este artículo se busca evaluar la calidad de los puestos de trabajo que se crearon en en el Estado de Bahia entre los años de 2000 y 2010 a partir de las estadísticas relativas a la evolución del trabajo formal. El propósito es reunir evidencia que indique en qué medida estos puestos de trabajo, vistas en conjunto, se acercaron y/o se alejaron de algunos de los diferentes sentidos atribuidos al concepto de trabajo decente. Para hacer frente a esta tarea se utilizan los datos aportados por la Relación Anual de Informaciones Sociales (RAIS). La hipótesis que guía la construcción de los argumentos se basa en la idea de que el trabajo formal no pode ser tomado como sinónimo de trabajo decente. Eso es así porque a pesar de que el primer tipo de trabajo (socialmente protegido) se acerque y/o corresponda al paradigma del trabajo decente, ello no logra revelar, en su integridad, el sentido que el termo decente busca expresar.

Palabras-clave | Economía de Bahia; empleo formal; siglo XXI; trabajo decente; trabajo formal.

Código JEL | J21; J80; O17.

\section{Introdução}

Uma das questões que, nos últimos tempos, vem despertando o interesse da sociedade brasileira, e, por conseguinte, obtendo grande espaço na mídia, diz respeito à dinâmica da economia nacional no tocante à geração de postos de trabalho formais. Em anos recentes, foi frequente a veiculação de notícias dando conta de sucessivos recordes na geração desses postos de trabalho no país. No mais das vezes, o "encantamento" por essas informações é tão grande que elas são digeridas/assimiladas pelo grande público de forma acrítica, sem que sejam feitos maiores questionamentos sobre a qualidade desses postos de trabalho em termos, por exemplo, do rendimento que oferecem, bem como sobre a maneira como se distribuem setorialmente e espacialmente num dado território.

No caso específico da Bahia, torna-se imprescindível a tarefa de mudar esse quadro, uma vez que, para não fugir à sua tradição de pioneirismo, esse foi o primeiro estado subnacional, em todo o mundo, a se comprometer com a criação e promoção de uma agenda do trabalho decente. 
Assim sendo, é fundamental - inclusive para orientar a formulação de políticas públicas voltadas à promoção do chamado trabalho decente no território baiano, dentro do âmbito de atuação da referida agenda - que os pesquisadores interessados nessa temática possam produzir estudos que consigam captar determinadas nuances do mercado de trabalho nacional e baiano que não são avistadas quando o interesse é simplesmente produzir análises que se preocupam, tão somente, em descrever os fenômenos, sem, contudo, buscar-lhes compreender os seus verdadeiros sentidos. Estes, muitas vezes, contidos naqueles detalhes que não "saltam aos olhos" de pronto, só são captados depois de um esforço de "garimpagem" das informações.

Pois bem, em função da "armadilha" que pode resultar da associação direta e instantânea do conceito de trabalho decente à noção de formalização do trabalho, optou-se, neste artigo, por procurar nas estatísticas que dão conta da evolução do trabalho formal no estado da Bahia, entre os anos de 2000 e 2010, evidências que permitam avaliar a qualidade dos postos de trabalhos. Deste modo, espera-se ter elementos para perceber em que medida essas vagas, vistas em conjunto, aproximaram-se e/ou afastaram-se de alguns dos diferentes sentidos atribuídos ao conceito de trabalho decente.

Para dar conta da evolução do mercado de trabalho formal na Bahia, recorreu-se aos dados disponibilizados pela Relação Anual de Informações Sociais (RAIS). O uso dessa base encontra respaldo no fato de que essa é a mais importante fonte de informações sobre o mercado de trabalho formal brasileiro, não só pela abrangência dos vínculos que considera (estatutário, temporário, avulso e celetista), como também pela incorporação das declarações de todas as empresas, já que é um registro administrativo de caráter obrigatório a todos os estabelecimentos públicos e privados existentes no território nacional ${ }^{2}$.

Pontuadas essas questões, resta comentar que, além desta introdução e das considerações finais, o presente texto encontra-se estruturado em três partes. $\mathrm{Na}$ primeira, são apresentadas as razões de se implantar uma Agenda do Trabalho Decente na Bahia. Na segunda, são expostos os números que captam a dinâmica de crescimento econômico desse estado e o seu rebatimento sobre a evolução do estoque de emprego nos anos 2000, ao tempo em que se dá ênfase à discussão de alguns pontos que permitem avaliar a qualidade dos empregos formais gerados. $\mathrm{Na}$ terceira, descreve-se como o crescimento do emprego se distribuiu nos 26 territórios de identidade baianos.

\footnotetext{
${ }^{2}$ Cabe mencionar também que, além de permitir a geração de estatísticas sobre o mercado de trabalho formal, a RAIS viabiliza o pagamento do Abono Salarial, presta subsídios ao Fundo de Garantia por Tempo de Serviço (FGTS) e à Previdência Social, ajuda a controlar a nacionalização de mão de obra e auxilia o Ministério do Trabalho e Emprego (MTE) na definição das políticas de formação e qualificação profissional.
} 


\section{Razões para implantar uma agenda do trabalho decente no Brasil e na Bahia}

Quando se parte da definição do que venha a ser trabalho decente - aquele "[...] adequadamente remunerado, exercido em condições de liberdade, equidade e segurança, capaz de garantir uma vida digna" (MTE, 2006, p. 5) - percebe-se, de imediato, que a economia brasileira, em geral, e a baiana, em particular, constituem campos férteis para iniciativas que promovam a expansão desse tipo de trabalho. Com efeito, há muito tempo, os estudiosos das relações de trabalho no Brasil chamam atenção para o elevado grau de heterogeneidade do mercado de trabalho nacional.

Existe certo consenso entre eles de que o desenvolvimento econômico observado na economia brasileira, alicerçado, sobretudo, no processo de industrialização, não trouxe a homogeneização das condições socioeconômicas, notadamente daquelas que se estabelecem nesse mercado. Sobre esta questão, Pochmann (2010, p. 21) argumenta:

\footnotetext{
De maneira geral, as relações de trabalho nos países que conformam a periferia do capitalismo mundial não registram idêntica trajetória de avanços, conforme observado em alguns poucos países desenvolvidos. Por conta disso, a evolução do trabalho no Brasil apresenta especificidades que não devem ser menosprezadas no âmbito da reprodução das principais características do subdesenvolvimento (disparidade na produtividade setorial e regional e parcela significativa da população prisioneira de condições precárias de vida e trabalho).
}

Em função desse panorama, mesmo diante da atual, tão propalada, expansão do emprego formal na economia nacional, ainda é muito pouco representativa a participação, por exemplo, de trabalhadores assalariados com registro em carteira no conjunto da ocupação do país. Com base nos dados disponibilizados pelo Censo Demográfico, para o ano de 2010, pouco menos de $1 / 2$ (48,1\%) dos ocupados brasileiros exerciam atividades laborais como assalariados com carteira.

Essa, no entanto, não é uma realidade exclusiva do Brasil. Outros países da América Latina também não conseguiram difundir amplamente o emprego formal nas suas economias. Na interpretação de Dedecca; Baltar (1997, p. 67-68), as causas dessa fragilidade podem ser avistadas em três frentes. A primeira relacionase ao fato de que o processo de modernização levado a cabo nas economias dessa região não resultou na ampliação do grau de assalariamento. A segunda tem a ver com o fato de que o processo de transformação econômica pelo qual passaram os países dessa região não suscitou alterações de grande monta no plano da 
organização social. A terceira, por sua vez, encontra-se na combinação de fatores de ordem econômica e política, os quais não perpetraram uma organização do Estado e da sociedade capaz de equacionar as grandes chagas que marcam os países de tal região: as questões agrária, regional, urbana e das políticas sociais.

O delineamento desse quadro conduz, portanto, ao entendimento de que o problema da exclusão econômica e social na América Latina tem a sua origem na não definição de uma estratégia de homogeneização social que permita o surgimento de um mercado de trabalho menos fragmentado. Em função desse estado de coisas é que os países dessa região não conseguiram deflagrar um esquema de amplificação das relações assalariadas, sujeitas à proteção social, a chamada standard employment relationship, como foi o caso, por exemplo, dos países de capitalismo avançado.

Assim sendo, tornava-se imperiosa a necessidade de se fomentar no país iniciativas que tentassem modificar essas fragilidades estruturais que se faziam presentes no mercado de trabalho brasileiro. Para fazer frente a esse desafio, teve lugar, em 2006, a Agenda Nacional do Trabalho Decente, a qual está em consonância com a Agenda Hemisférica, e possui quatro pilares estratégicos: "respeito às normas internacionais do trabalho, em especial aos princípios e direitos fundamentais do trabalho (liberdade sindical e reconhecimento efetivo do direito de negociação coletiva, eliminação de todas as formas de trabalho forçado, abolição efetiva do trabalho infantil, eliminação de todas as formas de discriminação em matéria de emprego e ocupação); extensão da proteção social; diálogo social; e promoção do emprego de qualidade." (MTE, 2006, p. 5).

A elaboração dessa Agenda Nacional suscitou repercussões importantes no plano subnacional. Tanto foi assim que, logo em 2007, o estado da Bahia, onde grassam relações de trabalho que se afastam dos princípios que norteiam a definição do trabalho decente, encampou ações que desembocaram na construção de uma Agenda que visa à superação/amenização das fragilidades estruturais do seu mercado de trabalho, entre as quais se pode destacar: a generalização do desemprego por praticamente todos os segmentos sociais; a grande proporção de trabalhadores assalariados sem carteira assinada e conta própria, o reduzido percentual de contribuintes para o instituto de previdência; o pagamento de baixas remunerações.

Diante desse panorama, fica evidente o déficit de trabalho decente com o qual a Bahia se depara. Foi exatamente em função da existência desse problema homérico que as autoridades governamentais da Bahia, articuladas com representantes da Organização Internacional do Trabalho (OIT), dos sindicatos patronais e de trabalhadores, bem como de outras instituições da sociedade civil organizada, criaram, em 2007, uma Agenda do Trabalho Decente. Embora plenamente afinada tanto com a Agenda hemisférica quanto a nacional, a Agenda baiana guarda as suas particularidades, posto que está estruturada em oito eixos, 
ou linhas de ação: trabalho doméstico; segurança e saúde no trabalho; juventude; erradicação do trabalho infantil; serviço público; promoção da igualdade; eliminação do trabalho escravo e empregos verdes (BAHIA, 2007).

Tal qual explicitado na Agenda Bahia, a efetivação dos termos contidos nas referidas linhas de ação é condição sine qua non para que o estado consiga diminuir o seu enorme passivo social, caminhando, assim, na direção de um desenvolvimento menos excludente, em que o crescimento econômico possa resultar não apenas na geração de ocupação e renda, mas que essas ocupações possam se desenvolver em condições tais que se traduzam em meios concretos para se alcançar condições de vida digna (BAHIA, 2007).

\section{Crescimento da economia baiana: reflexos sobre o estoque de emprego}

As políticas macroeconômicas levadas a cabo no plano nacional, nos anos 2000, exerceram, assim como em outros tempos, um papel fundamental na definição das principais características do panorama social baiano. Basta olhar, por exemplo, para o mercado de trabalho desse estado para verificar que a sua dinâmica foi fortemente condicionada pela política dos governos Cardoso e Lula.

Dito isto, pode-se afirmar, com base nas estatísticas disponíveis, que a Bahia, no período que cobre os anos de 2000 a 2010, contabilizou expansão da atividade econômica $(45,4 \%)$ superior a que foi medida nacionalmente $(42,6 \%)$. O registro desse acontecimento é, indiscutivelmente, o fato que mais ajuda a explicar a maior expansão relativa do estoque de emprego formal na Bahia $(81,7 \%)$ vis a vis aquela que foi apurada para o Brasil (68\%). No caso da Bahia, especificamente, saiu-se de uma situação em que o estoque de emprego correspondia, no ano de 2000, em números absolutos, a 1.177.343 postos de trabalho, e passou a corresponder a 2.139.232 postos de trabalho, em 2010, movimento esse que indica, portanto, um crescimento líquido do estoque de emprego da ordem de 961.889.

Perante essa realidade de crescimento concomitante do estoque de emprego e do PIB baianos, no período 2000-2010, encontra-se uma elasticidade-produto do emprego de 1,8. Isto significa que $1 \%$ de crescimento do PIB provocou uma expansão do emprego formal de 1,8\%. Essa elasticidade-produto do emprego na Bahia foi ligeiramente superior à medida no plano nacional $(1,6)$. Este número denota que a cada 1\% de crescimento do PIB nacional, o emprego ampliou-se em $1,6 \%$.

Vale salientar que, no transcorrer desse período, apenas os estados de São Paulo, Minas Gerais, Rio de Janeiro e Paraná tiveram desempenhos, em termos absolutos, melhores do que a Bahia no que diz respeito à geração de vagas no mercado de trabalho formal. No contexto nordestino, a representatividade da 
Bahia foi também destacada nesse particular, uma vez que respondeu por $26,5 \%$ de toda a variação absoluta do estoque de emprego (3.635.989 postos).

Esse desempenho da economia baiana na criação de postos de trabalho implicou, no entanto, um discreto incremento da sua participação relativa no contexto do emprego formal em âmbito nacional. Em 2000, a Bahia respondia por 4,5\% de todo o estoque do emprego formal existente no país (26.228.629 postos) e passou, em 2010, a responder por 4,9\% do referido estoque. Segundo esse parâmetro, o mercado de trabalho formal baiano também ocupava, em 2010, uma posição destacada, o sexto lugar (coincidente com o que ocupa nacionalmente quando o assunto se refere à produção de bens e serviços), uma vez que apenas os estados de São Paulo (29,2\%), Minas Gerais (10,5\%), Rio de Janeiro (9,3\%), Rio Grande do Sul $(6,4 \%)$ e Paraná $(6,3 \%)$ registravam percentuais maiores do que o encontrado para a Bahia.

É importante assinalar que essa elevação da participação relativa do emprego formal baiano no contexto nacional foi acompanhada de uma ampliação da participação relativa do estado na massa salarial paga aos trabalhadores formais brasileiros, posto que se saiu de uma situação, no ano de 2000 , em que os trabalhadores baianos se apropriavam de 3,5\% do total dessa massa, para outra, em 2010, na qual respondiam por 4\% dela ${ }^{3}$. Não obstante tenha sido registrada essa evolução, não se pode dizer que, no comparativo com as outras unidades da federação, a Bahia tenha melhorado de posição nesse particular. Isso porque quando se cria um ranking classificando tais unidades segundo a representatividade que possuem do ponto de vista da participação na massa salarial nacional, vê-se que a Bahia ocupava, em 2000, a sétima colocação e continuou a situar-se, em 2010, na mesma posição.

Debruçando-se um pouco mais sobre o comportamento da massa salarial, verifica-se que, em 2000, os trabalhadores formais baianos recebiam salários que, quando somados, totalizavam um montante de R \$1.329.864.026,93. Já em 2010, eles passaram a se apropriar de uma massa salarial que correspondia a $\mathrm{R} \$$ 2.831.564.923,98. Em função dessa dinâmica, a Bahia perdeu o posto, para Sergipe, de estado nordestino que pagava o mais alto salário médio. Em 2000, o rendimento médio dos trabalhadores baianos $(R \$ 1.134,90)$ era $5,7 \%$ superior ao pago no mercado de trabalho formal sergipano. Já em 2010, essa vantagem inverteu-se, haja visto que os trabalhadores sergipanos passaram a receber um rendimento de $R \$ 1.476,00$, valor este que se situava $10,5 \%$ acima do valor percebido pelos trabalhadores formais na Bahia.

Tal situação é emblemática, uma vez que se presta a lançar luz no debate que procura desvendar a qualidade dos postos de trabalho formais gerados no decorrer

\footnotetext{
${ }^{3}$ A rigor, todos os estados da região Nordeste também experimentaram essa mesma realidade vivenciada pela Bahia no que diz respeito à ampliação das suas respectivas participações relativas na massa salarial nacional.
} 
dos anos 2000 na Bahia. Com efeito, uma das questões mais relevantes nessa discussão refere-se à forma como se alterou a distribuição dos trabalhadores formais segundo as diferentes classes de rendimento - expressas em salários mínimos (SM) - no transcurso dessa década.

Efetivamente, não é descabido afirmar que nesse quesito a experiência dos trabalhadores não pode ser avaliada positivamente. Prova disso é encontrada no fato de que, em 2010, quase metade deles (47,4\%) auferiam rendimentos que alcançavam, no máximo, o patamar de 1,5 SM. Já em 2000, essa proporção situava-se num patamar bastante inferior $(31,6 \%)$.

Para compensar esse movimento de expansão da representatividade desse conjunto de trabalhadores no emprego estadual, registrou-se diminuição da participação relativa dos demais trabalhadores que integram as outras faixas de rendimento. Analisando-se especificamente a situação daqueles trabalhadores que estavam no topo da pirâmide de rendimento (recebendo mais de 20 SM), constatou-se o seguinte quadro: respondiam, em 2000, por 2,6\% do total de empregos e passaram a representar 1,1\%. Esse é um sinal inequívoco de que a referida ampliação do emprego formal na Bahia trouxe, no seu âmago, algumas vicissitudes para o mercado de trabalho, as quais, por razões óbvias, se afastam da premissa do trabalho decente.

Ao se pensar nas razões que poderiam justificar a referida mudança na distribuição de rendimentos, de início, poder-se-ia argumentar que ela poderia decorrer do fato de que, no período em questão, os trabalhadores formais baianos passaram a reunir, em conjunto, menores níveis de credenciais educacionais. Entretanto, as informações disponíveis mostram claramente que tal mercado tornou-se muito mais seletivo no que tange às exigências educacionais.

Indubitavelmente, as cobranças por níveis crescentes de escolaridade nas contratações formais foram percebidas pela forte diminuição da proporção de trabalhadores menos escolarizados, os quais possuíam, no máximo, o $1^{\mathrm{o}}$ grau completo. Em 2000, tais trabalhadores respondiam por $44,5 \%$ de todo o emprego formal estadual e passaram a representar, em 2010, apenas 24,9\%. Dentro deste grupo, foram os trabalhadores analfabetos os que, proporcionalmente, mais perderam participação no mercado de trabalho formal baiano, com uma variação negativa da ordem de 53,9\%. Para compensar esses movimentos, houve o incremento da participação relativa dos trabalhadores com melhores credenciais, ou seja, daqueles que possuíam níveis de escolaridade que variavam do $2^{\circ}$ grau incompleto até o superior completo.

Outra maneira de tentar justificar a citada alteração na distribuição do emprego formal por classes de SM é procurar descobrir o porte dos estabelecimentos que mais influenciaram a variação do estoque de empregos no estado. Uma hipótese razoável para conduzir a realização desse exercício é admitir que o referido rebaixamento do patamar salarial tenha decorrido do fato de que as empresas de 
menor porte - micro (4 a 9 funcionários), pequenas (10 a 49 funcionários) e médias (50 a 99 funcionários) - foram as maiores responsáveis pela variação no estoque de empregos, uma vez que nelas a produtividade do trabalho geralmente é menor, justificando o pagamento de salários mais baixos.

Todavia, as informações disponíveis desmentem a referida suposição, haja visto que foram os estabelecimentos considerados de grande porte (os que abrigam 100 ou mais funcionários) aqueles que contribuíram mais decisivamente para que o estoque total de empregos variasse na magnitude de 961.889 postos de trabalho. Precisamente, constatou-se que dessa variação, tais empresas responderam, em valores absolutos, por 581.405 postos de trabalho, o que, em termos relativos, significa $60,4 \%$.

Outro caminho que pode fornecer pistas importantes para se conseguir explicar o rebaixamento do padrão salarial do mercado de trabalho formal baiano, no período de tempo em questão, é a observação da evolução da distribuição do emprego nos diferentes setores da atividade econômica. Paradoxalmente, um resultado interessante que surge, quando se avança nessa direção, é que a Indústria de Transformação, setor historicamente reconhecido como pagador de boas remunerações, incrementou a sua participação na citada distribuição do emprego formal de 9,0\%, em 2000, para 10,5\%, em 2010. Quadro similar é também constatado no Comércio, posto que a sua participação saltou de 16,7\% para $18,1 \%$.

Realidade oposta a essa foi experimentada pelo setor de Serviços, dado que reunia $31,3 \%$ do estoque de emprego, em 2000, e passou, em 2010, a responder por $30,1 \%$, e por outros setores de menor expressão no contexto do emprego formal, a exemplo do Agropecuário. No caso específico desse último setor, observou-se a seguinte evolução: em 2000, absorvia 4,6\% dos trabalhadores formais do estado e, em 2010, passou a reunir 4\%. A constatação desse quadro é deveras preocupante, posto que uma parcela considerável dos trabalhadores baianos desenvolve atividades no setor primário ${ }^{4}$.

$\mathrm{Na}$ percepção de Santana (2003, p. 47), essa posição destacada do setor primário na ocupação estadual é decorrente

[...] de uma estrutura agrária na qual ainda se mantém uma proporção elevada de pequenas propriedades rurais, nas quais a produção para a subsistência envolve parcela significativa dos indivíduos que nelas vivem, o que contribui de maneira evidente para inflar o contingente de pessoas ocupadas em atividades agrícolas (embora à margem do circuito econômico propriamente dito).

\footnotetext{
${ }^{4}$ Em 2010, o Censo acusou que 26\% dos ocupados na Bahia desenvolviam atividades ligadas a agricultura, pecuária, produção florestal, pesca e aquicultura.
} 
Essa leitura está em perfeita sintonia com os resultados que constam em um estudo produzido pela SEI em 2005, no qual se investiga a situação dos 417 municípios baianos no que diz respeito às condições de operação e funcionamento dos seus respectivos mercados de trabalho. Nesse trabalho é possível constatar que na maioria esmagadora dos municípios baianos (315), o que corresponde, percentualmente, a $80,7 \%$ do total de municípios existentes no estado, a taxa de ocupação é igual ou superior a 80,0\%. Entretanto, a conformação desse quadro só é possível graças ao fato de que a inserção no mercado de trabalho baiano de uma parte significativa dos trabalhadores se dá por vias bastante precárias, tais como, trabalhadores não remunerados em ajuda a membros dos domicílios e trabalhadores na produção para o próprio consumo. Esse é notadamente o padrão que se verifica naqueles municípios que registram as menores taxas de desemprego, as quais, em muitos casos, indicam, inclusive, situações que se aproximam e/ou expressam o pleno emprego da força de trabalho local.

Em que pese à mencionada ampliação da participação da Indústria de Transformação na esfera do emprego formal, a sua contribuição para a variação no estoque de emprego foi pequena (12,4\%), comparativamente a do setor de Serviços $(28,6 \%)$, o qual, conforme se viu, perdeu importância relativa no estoque total de empregos. Convertendo essas variações relativas em números absolutos, vislumbra-se que, do total de postos de trabalho correspondentes à variação no estoque de empregos, a Indústria de Transformação respondeu por 118.918, enquanto os Serviços totalizaram 274.817 postos.

Não há como negar que essa expansão do emprego formal na Indústria de Transformação guardou íntima correlação com o avanço dos investimentos industriais verificados no estado ao longo dos anos 2000. Nesse período, conforme mencionam Carvalho Júnior; Silva; Pessoti (2011), vieram para a Bahia inúmeras indústrias, das mais variadas áreas, atraídas pelas isenções fiscais. Entre elas destacam-se a Ford (e as sistemistas), a Veracel, a Monsanto e diversas indústrias calçadistas. Tais autores informam, apoiados em levantamento feito pela Secretaria de Indústria e Comércio e Mineração do Estado, que a Bahia foi palco, no período de 2000 a 2009, de investimentos da ordem de, aproximadamente, $\mathrm{R} \$$ 42 bilhões.

Pelo menos em tese, esses foram acontecimentos que tinham grande potencial para melhorar a qualidade dos postos de trabalho oferecidos aos trabalhadores baianos, uma vez que a indústria, além de pagar salários atrativos, comparativamente aos demais setores, costuma abrigar a maioria das relações de trabalho que estabelece no "guarda-chuva" da formalização. Todavia, não se pode assumir essa suposição ao pé da letra, tendo em vista as idiossincrasias que caracterizam essa expansão do emprego no setor industrial baiano.

Uma delas é, indubitavelmente, o fato de o segmento calçadista ter sido o segundo maior destaque dentro desse setor no que se refere à geração de postos de 
trabalho, sendo responsável por 16,6\% de toda a variação de emprego registrada na indústria (atrás somente da indústria de produtos alimentícios, que responde por $23 \%$ de todos os postos de trabalho no setor referido). Curiosamente, tal segmento, conforme atestam os dados disponibilizados pela RAIS, era aquele que, em 2010, apresentava a segunda pior remuneração. Em termos médios, em 2010, ele remunerava a mão de obra que empregava com um salário médio da ordem de $\mathrm{R} \$ 765,62$, valor esse que correspondia a 1,5 SM da época.

Outra característica peculiar dessa expansão é o descompasso entre a grandiosidade do volume de recursos financeiros exigidos pelos referidos investimentos industriais e a repercussão produzida sobre a geração de emprego. O Projeto Amazon, que trouxe a Ford para a Bahia, resume isso de modo exemplar. Comparando-se os estoques de emprego existentes na atividade Fabricação de veículos automotores, reboques e carrocerias, em 2000 e 2010, chega-se a uma variação de 10.549 postos de trabalho. Ou seja, um empreendimento que arregimentou cerca de U\$ 2 bilhões, proporcionou a abertura de menos de 11.000 vagas de trabalho.

A vinda dessa empresa para a Bahia gerou enormes expectativas quanto às possibilidades de expansão do mercado de trabalho formal. Especulava-se, a princípio, que a instalação de uma planta industrial como a da Ford implicasse a geração de 5.000 empregos diretos e 50.000 indiretos. Respeitadas as devidas tessituras, imaginava-se que esse evento pudesse impactar o mercado de trabalho baiano de forma semelhante ao ocorrido em tempos pretéritos, quando foram fincadas as bases da indústria do petróleo.

Seria, portanto, uma espécie de reedição do processo de redenção a que foi submetida à economia baiana nos idos de 1950 - tão brilhantemente comentado por Guimarães (2002) -, com o surgimento de novos atores, quais sejam, a indústria automobilística e os seus trabalhadores. Estes últimos, possíveis integrantes de uma classe média que ajudaria a dinamizar os contornos dessa economia, notadamente na sua faixa metropolitana.

Por certo, esses rebatimentos seriam bem mais intensos se os trabalhadores pertencentes a essa indústria na Bahia tivessem a mesma condição salarial dos seus congêneres de São Paulo. Nesse particular, é flagrante a desvantagem dos trabalhadores locais, haja visto que auferiam um salário médio, em 2010, de R\$ 2.825,52, valor esse que representava apenas $80,5 \%$ do salário médio dos trabalhadores paulistas $(\mathrm{R} \$ 3.509,80)$.

Vale notar que essa discrepância não encontra respaldo, por exemplo, no argumento de que a planta da Ford, em Camaçari, utiliza-se de tecnologias de produção menos sofisticadas do que as presentes na indústria automobilística paulista, o que, inequivocamente, em rebatendo sobre a produtividade dos trabalhadores, justificaria o pagamento de remunerações mais baixas. Pelo que se sabe, o padrão tecnológico do Projeto Amazon rivaliza com as "melhores" 
práticas internacionais. Daí não dá para supor que os trabalhadores que operam tal planta sejam menos qualificados e, por conseguinte, menos produtivos. A velocidade com que se atingiu a capacidade máxima de produção na planta de Camaçari desmente e/ou enfraquece argumentações em contrário.

A julgar pela mobilização de recursos envolvidos nos investimentos industriais que aportaram na Bahia, as repercussões no emprego desse setor foram bastante tímidas, muito embora tenha havido, como já destacado, expansão da sua participação no contexto do emprego estadual. Prova disso pode ser encontrada no fato de que o patamar de representação no estoque de emprego total atingido, em 2010, era apenas ligeiramente superior àquele verificado em meados dos anos 1990, quando o setor respondia por 9,6\% dos empregos formais da Bahia. Inquestionavelmente, dois fatores contribuíram para a configuração desse quadro: a elevadíssima intensidade em capital e o limitado encadeamento produtivo dos investimentos realizados.

\section{Aspectos da distribuição espacial do emprego formal}

Um aspecto que precisa ser destacado quando se analisa a evolução do emprego formal no período em questão é que os municípios que integram o Território de Identidade Metropolitano não foram aqueles que se responsabilizaram pela maior parte dos empregos gerados. Essa posição destacada coube aos municípios localizados no interior. Em números absolutos, tem-se que daquelas 961.889 vagas abertas no mercado de trabalho formal baiano entre 2000 e 2010, 351.041 foram geradas no referido território e as 606.848 restantes no interior. Isso equivale a dizer que, do ponto de vista percentual, esse primeiro espaço concentrou 36,9\% das vagas, enquanto o segundo ficou com os outros $63,1 \%$.

Em 2000, o Território de Identidade Metropolitano contabilizava um estoque de emprego formal da ordem de 698.237 postos de trabalho, número esse que representava 59,3\% de todo o estoque de emprego existente no conjunto do estado. No ano de 2010, apurava-se para esse mesmo território um estoque de emprego de 1.053.278 postos de trabalho. Nesta oportunidade, esse conjunto de empregos representava $49,2 \%$ de todo o estoque de emprego medido no plano estadual.

Compensando esse movimento de queda de participação do Território Metropolitano no contexto do emprego formal estadual, quase todos os outros territórios de identidade incrementaram as suas respectivas participações. A única exceção ficou a cargo do Território de Litoral Sul.

Outra informação importante que salta aos olhos quando se procura detalhar os fatores que contribuíram para que a Bahia apresentasse essa dinâmica no crescimento do emprego formal na década passada é que o número de 
estabelecimentos, públicos e privados, existentes que empregavam trabalhadores de maneira formal passou de 93.763, em 2000, e atingiu o patamar de 167.170, em 2010, movimento que equivaleu a uma variação relativa da ordem de 78,3\%.

Um dos prováveis eventos que contribuiu para que o Território Metropolitano viesse a perder espaço no contexto do emprego formal baiano está relacionado ao fato de que nele ocorreu um processo de diminuição relativa do número de estabelecimentos entre os anos de 2000 e 2010 , pois enquanto nesse primeiro ano os seus 38.427 estabelecimentos correspondiam a cerca de $41,0 \%$ do total de estabelecimentos existentes no estado, no segundo os seus 167.130 estabelecimentos passaram a equivaler a $35,1 \%$ do total de estabelecimentos presentes no plano estadual. Apenas em mais outro Território de Identidade (Litoral Sul) observou-se movimento semelhante. Todos os outros Territórios de Identidade ou mantiveram sua representatividade nesse esquema ou a ampliaram.

O desenho desse novo arranjo da distribuição dos empregos formais e dos estabelecimentos que empregam trabalhadores pelas vias da formalidade impõe o exercício de algumas reflexões. Com efeito, foi deveras salutar o incremento da participação relativa dos municípios baianos que integram outros Territórios de Identidade que não o Metropolitano no contexto do emprego formal. Sem dúvida, esse foi um acontecimento que espelha o quadro de desconcentração espacial da atividade produtiva na Bahia, evidenciado pelos números do PIB municipal baiano de 2008.

Após uma análise acurada desses números, Pessoti et al. (2009) chegaram à conclusão de que houve um ganho de participação para os municípios fora da Região Metropolitana de Salvador. Mesmo com essa alteração, continua efetiva a macrocefalia do Território Metropolitano no que se refere ao PIB e, por conseguinte, do emprego formal. Trata-se de uma situação em que, conforme se viu, apenas dez municípios (Salvador, Camaçari, Lauro de Freitas, Simões Filho, Candeias, Dias d'Ávila, Vera Cruz, Itaparica, Madre de Deus e Salinas da Margarida), de um total de 417 existentes na Bahia, ainda respondiam, em 2010, por pouco menos da metade dos empregos formais. Por outra via, atenta-se que outros dez municípios do Estado, aqueles com maiores estoques de emprego formal, detiveram em 2010, mais de 60,5\% de toda força de trabalho da Bahia. Desses, quatro pertencem ao Território Metropolitano de Salvador (Salvador, Lauro de Freitas, Camaçari e Simões Filho), outros dois do Território de Identidade Litoral Sul (Itabuna e Ilhéus) e os demais de Territórios distintos (Feira de Santana, Vitória da Conquista, Juazeiro e Barreiras). 


\section{Considerações finais}

O esforço interpretativo aqui empreendido para acompanhar a evolução do emprego formal na Bahia no período 2000/2010 não teve, ao chamar a atenção para algumas vicissitudes que encerra, a finalidade de desqualificá-la. O investimento feito nessa direção teve tão somente o intento de evidenciar algumas questões que muitas vezes ficam encobertas quando são apresentados os grandes números que dão conta do fenômeno da formalização do mercado de trabalho brasileiro, de uma forma geral, e baiano, em particular.

Ao privilegiar essa conduta interpretativa, foi possível notar que tal formalização, nesse intervalo de tempo, implicou algumas ocorrências que impedem a sua associação à ideia do trabalho decente. Em verdade, pelas informações analisadas pode-se observar certas nuances dessa formalização que se afastam, por assim dizer, da perspectiva do que venha a ser efetivamente um trabalho decente.

Como afirmar que o trabalho formal na Bahia evoluiu de modo a afinar-se plenamente com as prerrogativas contidas na sua Agenda do Trabalho Decente? Efetivamente, o desiderato de que a formalização melhorasse integralmente a qualidade do emprego na Bahia não se confirmou. Prova maior disso foi o fato de (mesmo levando em conta que, no Governo Lula, o SM passou por um processo de valorização) ter crescido a proporção de trabalhadores baianos que ganhavam no máximo até 1,5 SM.

O registro dessa ocorrência força obrigatoriamente a discussão em torno da questão da qualidade dos empregos formais que foram gerados na Bahia nesse período, ao tempo em que remete a uma problemática extremamente importante quando se reflete sobre as aspirações baianas quanto ao desenvolvimento econômico e social, qual seja, o tipo de expansão capitalista aqui vivenciada. Esta, em que pese ter provocado impactos importantes do ponto de vista da geração de emprego formal, não pode ser entendida como excepcionalmente benfazeja para os trabalhadores baianos. Isso porque resultou num esquema de rebaixamento do padrão salarial que fez, inclusive, a economia baiana perder a condição, para Sergipe, de estado nordestino que pagava o melhor salário aos empregados do setor formal.

Pelo panorama descrito, as mudanças observadas no padrão dessa expansão capitalista na Bahia foram tímidas. Como sempre, o Território Metropolitano continuou acolhendo (motivada por economias de aglomeração, decorrentes da insuficiência de infraestrutura no interior do estado e dos custos de escoamento da produção), para usar uma linguagem popular, o filet mignon dos investimentos produtivos na Bahia. Os investimentos, notadamente os industriais, dirigidos para as outras partes do estado produziram impactos na geração de postos de trabalho formais de pequena monta. Quanto ao volume, o principal destaque, nesse particular, ficou a cargo do segmento calçadista. Porém, tal segmento se diferencia 
dos demais por ser aquele que remunera os trabalhadores com o segundo salário médio mais baixo.

Ante o exposto, permanece o secular desafio da sociedade baiana, agora documentado nos termos que definem a sua Agenda do Trabalho Decente, que é não apenas aumentar a produção da riqueza material e, portanto, gerar emprego e renda, mas, sobretudo, encampar ações que promovam a melhoria das condições de reprodução da sua força de trabalho. O desafio é hercúleo. Até mesmo quando as sinalizações parecem indicar a reversão das condições estruturais de fragilização do mercado de trabalho baiano, com a expansão da sua fatia formalizada, um olhar mais acurado se incumbe de desmenti-la.

\section{Referências}

BAHIA. Governo da Bahia. Secretaria do Trabalho, Emprego, Renda e Esporte. Agenda Bahia do Trabalho Decente. Salvador: Governo da Bahia, 2007. 17 f. Disponível em: <http://www2.setre.ba.gov.br/trabalhodecente/agenda_bahia _do_trabalho_decente.pdf $>$. Acesso em: 10 nov. 2010.

CARVALHO JÚNIOR, C.; SILVA, D.; PESSOTI, G. Análise da evolução da economia na Bahia entre 1975 e 2010 sob o novo enfoque de contas regionais. Bahia Análise \& Dados, v. 21, n. 1, p. 215-234, 2011.

DEDECCA, C; BALTAR, P. Mercado de trabalho e informalidade nos anos 90. Estudos Econômicos, v. 27, n. especial, p. 65-84, 1997.

GUIMARÃES, N. Reestruturação sistêmica e mobilidade predatória: destino de trabalhadores em espaços sociais sob intensa mudança. In: LIMA, Paulo Costa (Coord.). Quem faz Salvador. Salvador: UFBA, p. 269-285, 2002.

MTE. Agenda Nacional do Trabalho Decente. Brasília: MTE, 2006. 19 p. Disponível em: <http://www.oit.org.br/node/298>. Acesso em: 8 nov. 2010.

PESSOTI, G.; SANTOS, J.; SILVA, K.; PEREIRA; S. PIB municipal revela leve desconcentração espacial na economia baiana. Conjuntura \& Planejamento, n. 165 , p. 58-67, 2009.

POCHMANN, M. Trabalho em questão neste início de século XXI. Série Estudos e Pesquisas, v. 86, p. 11-25, 2010.

SANTANA, Marcelo. Mudanças nas formas de inserção da população ocupada na Bahia dos anos 1990. Série Estudos e Pesquisas, Salvador, v.59, p.45-64, 2003. 
Laumar Neves de Souza

Endereço para correspondência:

LaumarNevesdeSouza - laumar.souza@unifacs.br Rua Doutor José Peroba, 251

41770-235 Salvador/BA, Brasil

172 | Revista Brasileira de Desenvolvimento Regional, Blumenau, 1 (2), P. 157-172, primavera de 2013 